\title{
Effect of dietary guild (frugivory and insectivory) and other host characteristics on ectoparasite abundance (mite and nycteribiid) of chiropterans
}

\author{
Albert Luguterah $^{1}$ and Eric Adjei Lawer ${ }^{1,2}$ \\ ${ }^{1}$ Department of Statistics, University for Development Studies, Navrongo, Ghana; \\ ${ }^{2}$ Department of Range and Wildlife Management, University for Development Studies, Tamale, Ghana
}

\begin{abstract}
Ectoparasites are an important factor in bat health due to emergent diseases and their associated threats to global public health. The diverse foraging habits of bats expose them to different surfaces which may influence ectoparasite infestations. In spite of these, most studies often overlook dietary specialisations when observing ectoparasite loads. The present paper quantitatively investigates whether foraging strategies as well as other host characteristics (sex, age, trunk and patagial area) influence ectoparasite (nycteribiids and mites) loads of bats. Ectoparasite counts and morphometric data were taken from mist net captures of bats. We then developed and compared models for modeling bat ectoparasite abundance under various distributions using generalised linear models. The negative binomial distribution consistently proved to be adequate for modeling mite, nycteribiid and total ectoparasite abundance based on information-theoretic approaches. Generally, females and frugivores had higher ectoparasite loads conditional on bat sex and diet, respectively. Contrary to nycteribiid abundance, mite abundance was positively related to patagial area. Thus, our findings suggest that dietary guild, sex and patagia of hosts (as well as age-nycteribiid abundance) are significant determinants of ectoparasite abundance.
\end{abstract}

Keywords: mammal, negative binomial, parasitism, Poisson, Zero Inflated Negative Binomial, Zero Inflated Poisson

Ectoparasites are present on almost all species of mammals including bats (Ritzi and Whitaker 2003). Bat flies and mites are common ectoparasites of bats. The relative mobility of different ectoparasite species would therefore favour movement of more mobile species (e.g. bat fleas such as nycteribiids) than less mobile species (e.g. mites). As such bats demonstrate a wide range of avoidance and defense strategies in response to parasites or the threat of being parasitised (Marshall 1981, Lehane 2005, Reinhardt and Siva-Jothy 2007). Behavioural, morphological and physiological traits are among such strategies exhibited by mammals. Avoidance of infested areas in favour of roost and forage sites which are unfavourable for ectoparasites are some of the responses of hosts to parasitism as has been reported for a variety of animals (Hart 1992).

Another means by which animals can reduce ectoparasite loads is host grooming. This behavioural response to ectoparasitism is a major cause of ectoparasite mortality or departure from hosts. Studies conducted on animals such as pigeons (Clayton et al. 1999) and cats (Eckstein and Hart 2000) have been used to demonstrate the relationship between host grooming and ectoparasite abundance. Thus there is increased host grooming with increased ectoparasite abundance and increased ectoparasite abundance fol- lowing the prevention of host grooming. Although this behavioural strategy is effective, it comes at a cost resulting in for instance hair loss (Mooring and Samuel 1999) and increased energy budget (Giorgi et al. 2001). Hence grooming may be more costly for young bats with restricted energy budgets.

Due to the ecologically and geographically isolated nature of their hosts (Wenzel and Tipton 1966) as well as life history strategies of parasites (Marshall 1981), many ectoparasite of bats are highly host specific. Most ectoparasites of bats show strong coevolutionary ties to their host because they never or only briefly leave the host (Lučan 2006, Dick 2007, Bruyndonckx et al. 2009). Several life history traits of hosts may influence the prevalence and intensity of ectoparasites (Fitze et al. 2004, Morand et al. 2004). For example, lactating female bats in maternity colonies have a higher prevalence and intensity of ectoparasites than nonlactating females (Christe et al. 2000, Reckardt and Kerth 2009). Although ectoparasitism has been reported to reduce fitness (Brown and Brown 1986, Lehmann 1993), it does not cause host mortality in most cases (Marshall 1981, Clayton 1991).

Generally, females of mammalian species harbour less ectoparasites than do males (Moore and Wilson 2002) due 
to sex-based differences in immunocompetence or home range size (Morand et al. 2004, Krasnov et al. 2005). The immunocompetence hypothesis, which was proposed by Folstad and Karter (1992), suggests that testosterone may have a dual effect. Thus, while increasing investment in sexually selected characters it may simultaneously compromise the immune system.

Despite studies that have investigated the factors explaining the diversity of bat ectoparasites, such as colony size or roosting behaviour (Bordes et al. 2008, Gay et al. 2014), none of them had considered the foraging strategies of bats. Hence, the goal of the present study was to quantitatively investigate the determinants of ectoparasite loads on bats. Specifically, we hypothesised that ectoparasite intensity will vary among bat dietary habits (frugivores and insectivores). Thus diverse foraging strategies of bats expose them to different types of foliage, animals and numbers of conspecifics which may influence ectoparasite infestations. Foraging habits have been shown to influence pathogen transmission risk due to an increased likelihood of vertebrates to ingest contaminated food or infected prey (Bell and Burt 1991, Vitone et al. 2004). Rosenzweig (1995) reported that larger habitats support more individuals (and species) than do smaller habitats. We therefore hypothesised that if host body size is analogous to habitable area, then larger hosts should have a higher prevalence and intensity of ectoparasites than do smaller hosts. Also, we expect that host characteristics such as sex and age would determine the intensity and prevalence of ectoparasites.

\section{MATERIALS AND METHODS}

\section{Study area}

The study was conducted at Kosane in the Dormaa West district of the Brong Ahafo Region, Ghana. The district was carved out of Dormaa which lies within longitude $3^{\circ}-3^{\circ} 30^{\prime} \mathrm{W}$ and latitude $7^{\circ}-7^{\circ} 30^{\prime} \mathrm{N}$. The vegetation is characterised by unused forests, broken forests, grasslands and extensively cultivable forestlands and forest reserves. It has a bimodal rainfall pattern with a dry spell that spans from November to February. Mean annual rainfall values in the area are between $1,250 \mathrm{~mm}$ and $1,750 \mathrm{~mm}$ with an average temperature of $26.1^{\circ} \mathrm{C}-30^{\circ} \mathrm{C}$ (Dormaa Municipal Assembly 2006).

\section{Capture of bats and collection of ectoparasites}

Bats were captured with the aid of $12 \times 2.5 \mathrm{~m}$ mist nets set at ground level at identified fly ways in three of each agroecosystem type (citrus farms, mixed farms, fallow lands, teak plantations, oil palm plantations, maize farms) following a reconnaissance survey. Mist nets were monitored periodically from 18:30 hours each day until they were closed at 02:00 hours the following day. Each captured bat was marked to avoid double sampling and then released at the same site of capture. During this period, species identification and morphometric (body mass and forearm length) measurements of chiropterans were carried out. Species were later classified into two foraging guilds based on diet (Hill and Smith 1984, Giannini and Kalko 2004) for analyses. Fruit-eating bats were classified as frugivores whiles insect-eating bats were classified as insectivores. Sexing of individuals was based on the presence of male external genitalia (Racey 1988). Captured bats were later classified into three age groups namely; juveniles, subadults and adults (Nelson 1965, Vardon and Tidemann 1998, Holmes 2002). In addition, ectoparasites were removed from bats with the aid of forceps and preserved in vials of $70 \%$ ethanol for identification. To prevent the possibility of ectoparasite escapes, a cloth was held around the body of each captured bat while removing the parasites. In order to avoid contamination of samples, a cloth bag was used for each bat sampled. These cloth bags were later washed and inspected before re-use.

\section{Data analysis}

A total of 183 ectoparasites (57 mites and 126 nycteribiids) were identified on 253 captured chiropterans (bats) during the research period. This comprised of 128 frugivorous (Epomops buettikoferi Matschie, Lissonycteris angolensis Bocage, Micropteropus pussilus Peters and Rousettus aegyptiacus Geoffroy St.-Hilaire) and 125 insectivorous bats (Hipposideros aff. ruber Noack, Hipposideros jonesi Hayman and Nycteris spp.) pooled based on diet and or family (with the exception of Nycteris spp.) for the purpose of this study. A preliminary test (nested randomeffects analysis of variance) performed to determine the distribution of variance phylogenetically (species within genus within family) based on square root transformed total ectoparasite counts revealed that most of the variation was centred around genera $(34 \%, \mathrm{P}<0.0001)$ and families $(45 \%, \mathrm{P}=0.0411)$. Though it was envisaged that genera of higher taxa essentially pooled diverse lineages, we opted to use two species as the unit of analysis due to the small size of the dataset based on species within genera and genera within families. The two species, namely L. angolensis (family Pteropodidae) and $H$. jonesi (family Hipposideridae), which have distinct dietary specialisations, belong to the same sub-order 'Pteropodiformes'.

The patagia or trunk of hosts are common areas where many species of ectoparasites are located. Body mass and forearm length were therefore used as alternate measurements of body size. Since these two parameters do not have a linear relationship with surface area, the criteria of Emerson et al. (1994) was adopted for the ectoparasite study. Patagial area and host trunk area were therefore estimated (scaled) using forearm length ${ }^{2}$ and body mass $^{2 / 3}$, respectively, for the analysis.

\section{Generalised linear models}

The minimum and maximum counts of ectoparasite infestations per individual chiropteran ranged from zero (no infestation) to ten (high infestation). Thus, close inspection of the entire body surface of chiropterans for ectoparasite infestation or abundance will generate a non-negative integer or count data which will thus be inappropriate for traditional linear modeling. Insisting on their use may result in the prediction of negative counts, nonnormality of errors and the possibility of the variance increasing with the mean (model misspecifications and inconsistent estimators). Generalised Linear Models (GLM) are therefore extensions of Traditional Linear Models (TLM) formulated to accommodate responses with non-normal distributions as well as model functions of the mean (Agretsi 2002). Suppose a response variable with independent random observations $y_{1}, y_{2}, \cdots, y_{n}$ and expected response $E\left(y_{i}\right)=\mu_{\mathrm{i}}$. Then both the TLM and GLM will be defined by the linear component given below: 
Table 1. Tentative distributions used for modeling ectoparasite counts of the comparative study between two chiropteran species (Lissonycteris angolensis Bocage vs Hipposideros jonesi Hayman) with different foraging habits.

\begin{tabular}{lcccccc}
\hline \multirow{2}{*}{ Distribution } & \multicolumn{2}{c}{ Mite abundance } & \multicolumn{2}{c}{ Nycteribiid abundance } & \multicolumn{2}{c}{ TE abundance } \\
\cline { 2 - 7 } & $A I C_{C}$ & $B I C$ & $A I C_{C}$ & $B I C$ & $A I C_{C}$ & $B I C$ \\
\hline Poisson & 182.99 & 200.33 & 292.42 & 309.76 & 349.64 & 366.98 \\
NB & $158.40^{*}$ & $178.04^{*}$ & 289.50 & $309.14^{*}$ & $336.18^{*}$ & $355.82^{*}$ \\
ZIP & 166.15 & 198.45 & 288.76 & 321.07 & 344.39 & 376.70 \\
ZINB & 173.90 & 204.20 & 307.60 & 337.90 & 362.30 & 392.60 \\
\hline
\end{tabular}

$A I C_{C}$ - Akaike Information Criterion; BIC - Bayesian Information Criterion; NB - Negative Binomial; TE - Total ectoparasite; ZINB - Zero Inflated Negative Binomial; ZIP - Zero Inflated Poisson; * best model based on selection criteria.

$$
\eta_{i}=\beta_{0}+\beta_{T} x_{i 1}+\cdots \beta_{k} x_{i k}=x \beta
$$

where;

$\eta_{\mathrm{i}}$ is the linear predictor

$X_{i}$ is the design matrix and

$\beta$ is the vector of unknown parameters

However, one distinguishing criterion between TLM and GLM is that GLM are characterised by a monotonic differentiable link function, $g$. The link function describes how the expected response is related to the linear predictor and is given by;

$$
g\left(\mu_{i}\right)=X \beta=\eta_{i}
$$

These response variables $y_{i}$ are considered to have probability distributions from the exponential family. In this study, a logarithmic link function was incorporated into the GLM to produce predicted values of the response that are permissible (and help check for overdispersion). The Poisson, Negative Binomial (NB), Zero Inflated Poisson (ZIP) and the Zero Inflated Negative Binomial (ZINB) distributions were used in this study to investigate the determinants of ectoparasite abundance.

Both the Poisson and NB distributions assume that the variance, $\sigma^{2}$ is proportional to the expected response, $\mu$.

$$
\sigma^{2}=\phi E(y)=\phi \mu
$$

Principal to models with a Poisson distribution is the equality of variance and mean values such that $\phi=1$. If it is observed that $\phi>1$, the data indicate overdispersion and the converse is also true for underdispersion, $\phi<1$. The negative binomial distribution was specified to account for overdispersion relative to the Poisson distribution. The negative binomial distribution has a dispersion parameter $(k=1 / a)$ such that as $k$ approaches zero, $\sigma^{2}$ approaches $\mu$ and thus, over dispersion declines likening it to the Poisson.

The ZIP was also used to fit the excess zeros of the ectoparasite count as a mixture of two separate distributions. Thus one distribution is Poisson, generating zero and nonzero counts, while the second is a constant distribution generating only zero counts. When, on the other hand, overdispersion was still detected, the ZINB model was used as an alternative. This distribution has an underlying count distribution that is Negative Binomial.

\section{Model selection}

Akaike Information Criterion $(A I C)$, corrected Akaike Information Criterion $\left(A I C_{C}\right)$ and Bayesian Information Criterion $(B I C)$ are all measures of goodness of fit that were used to select the most adequate model. These model selection techniques penalise for the addition of parameters such that the model of best fit has a minimum number of parameters to ensure simplicity and parsimony. The model with minimum $A I C, A I C_{C}$ and $B I C$ in the class of competing models is thus considered best. The general computations for the $A I C, A I C_{C}$ and $B I C$ are given below:

$$
\begin{aligned}
& A I C=\log \left(\hat{\sigma}^{2}\right)+\frac{2 m}{N} \\
& A I C_{C}=A I C+\frac{2 m(m+1)}{N-m-1} \\
& B I C=\log \left(\hat{\sigma}^{2}\right)+\frac{m \log N}{N}
\end{aligned}
$$

where;

$\hat{\sigma}^{2}$ is the maximum likelihood estimate of residual term variance

$m$ is the number of parameters in the model and

$N$ is the total number of observations in the dataset

\section{RESULTS}

Based on the selection criteria, the Negative Binomial distribution was appropriate for modeling mite, nycteribiid and total ectoparasite abundance of chiropterans. Thus, the Negative Binomial distribution consistently recorded the least $B I C$ values compared to that of the Poisson, Zero Inflated Poisson and Zero Inflated Negative Binomial distributions in terms of the variables modeled (Table 1). The full and reduced models of the ectoparasite analyses are presented in Tables 2 and 3, respectively.

\section{Mite abundance}

Though the parameter estimates for juveniles (-6.7064, $\mathrm{P}=0.8649)$ and subadults $(-0.8376, \mathrm{P}=0.1169)$ were negative, they were not significantly different from adult chiropterans in terms of mite abundance. Also, the insignificant negative parameter estimate for host trunk indicates that for each one unit increase in host trunk area, the expected log count of the number of mites decreases by 0.0372 (Table 2). Due to the statistical insignificance of these two parameters (age and host trunk), a reduced model was fitted with only the significant variables as shown in Table 3. Based on the findings, the difference in the logs of mite counts is expected to be 1.7861 units lower for males compared to females, given that all other variables are held constant in the model. Furthermore, the expected $\log$ mite count for L. angolensis, which has a frugivorous diet, is 4.6605 higher than the expected log mite count for $H$. jonesi, which has an insectivorous diet. The significant estimate for patagia implies that for a unit increase in patagial area, the expected log count of the number of mites increases by 0.0020 . 
Table 2. Parameter estimates of ectoparasite abundance for the comparative analysis between Lissonycteris angolensis Bocage (frugivory) and Hipposideros jonesi Hayman (insectivory) based on sex, age, diet, host trunk and patagial area - full models employed appropriate distributions based on selection criteria in Table 1.

\begin{tabular}{|c|c|c|c|c|}
\hline Parameter & Estimate & Std. error & Wald $\chi^{2}$ & $P$-value \\
\hline \multicolumn{5}{|l|}{ Mite abundance } \\
\hline Intercept & -3.9710 & 1.8398 & 4.66 & 0.0309 \\
\hline Male & -1.6319 & 0.5333 & 9.36 & 0.0020 \\
\hline Female & 0.0000 & 0.0000 & - & - \\
\hline Juvenile & -6.7064 & 9.4226 & 0.03 & 0.8649 \\
\hline Subadult & -0.8376 & 0.5342 & 2.46 & 0.1169 \\
\hline Adult & 0.0000 & 0.0000 & - & - \\
\hline Frugivory & 3.6578 & 2.0964 & 4.08 & 0.0434 \\
\hline Insectivory & 0.0000 & 0.0000 & - & - \\
\hline Host trunk area & -0.0372 & 0.0889 & 0.17 & 0.6760 \\
\hline Patagial area & 0.0019 & 0.0007 & 6.56 & 0.0104 \\
\hline \multicolumn{5}{|c|}{ Nycteribiid abundance } \\
\hline Intercept & 2.6391 & 0.9517 & 7.69 & 0.0056 \\
\hline Male & -0.5565 & 0.2605 & 4.57 & 0.0326 \\
\hline Female & 0.0000 & 0.0000 & - & - \\
\hline Juvenile & 0.8046 & 0.3166 & 6.46 & 0.0110 \\
\hline Subadult & 0.1594 & 0.3945 & 0.16 & 0.6862 \\
\hline Adult & 0.0000 & 0.0000 & - & - \\
\hline Frugivory & 2.1969 & 0.8246 & 7.10 & 0.0077 \\
\hline Insectivory & 0.0000 & 0.0000 & - & - \\
\hline Host trunk area & -0.0631 & 0.0401 & 2.47 & 0.1159 \\
\hline Patagial area & -0.0007 & 0.0003 & 5.51 & 0.0189 \\
\hline \multicolumn{5}{|c|}{ Total ectoparasite abundance } \\
\hline Intercept & 1.3284 & 0.6455 & 4.23 & 0.0396 \\
\hline Male & -0.3653 & 0.1908 & 3.66 & 0.0556 \\
\hline Female & 0.0000 & 0.0000 & - & - \\
\hline Juvenile & 0.2045 & 0.2845 & 0.52 & 0.4723 \\
\hline Subadult & 0.4055 & 0.2754 & 2.17 & 0.1408 \\
\hline Adult & 0.0000 & 0.0000 & - & - \\
\hline Frugivory & 1.3983 & 0.5875 & 5.66 & 0.0173 \\
\hline Insectivory & 0.0000 & 0.0000 & - & - \\
\hline Host trunk area & -0.0413 & 0.0342 & 1.45 & 0.2278 \\
\hline Patagial area & -0.0003 & 0.0002 & 1.72 & 0.1897 \\
\hline
\end{tabular}

\section{Nycteribiid abundance}

From the results in Table 2, host trunk area was not a significant predictor of nycteribiid abundance. The reduced model in Table 3 shows that the expected log nycteribiid count for males is 0.5256 lower than that of females. Whereas the expected log nycteribiid counts for both juveniles and subadults were $0.9577(\mathrm{P}=0.0015)$ and 0.2233 $(\mathrm{P}=0.5718)$ higher than the expected log nycteribiid count for adults, respectively, only that of juveniles was statistically significant. Again, the expected log count for individuals with a frugivorous diet is 1.5739 higher than the expected log count for individuals with an insectivorous diet. Contrary to the chiropteran mite abundance model above, patagial area showed a significant negative relationship in terms of nycteribiid abundance suggesting a decline of the parasite in that 'area/locality'.

\section{Total ectoparasite abundance}

Since age, host trunk and patagial area were not significant predictors of total ectoparasite abundance (Table 2), a reduced model excluding these parameters was fitted (Ta-
Table 3. Parameter estimates of ectoparasite abundance for the comparative analysis between Lissonycteris angolensis Bocage (frugivory) and Hipposideros jonesi Hayman (insectivory) based on sex, age, diet, host trunk and patagial area - reduced/final model.

\begin{tabular}{lcccc}
\hline Parameter & Estimate & Std. error & Wald $\chi^{2}$ & $P$-value \\
\hline Mite abundance & & & & \\
Intercept & -4.4855 & 2.0475 & 4.80 & 0.0285 \\
Male & -1.7861 & 0.5593 & 10.20 & 0.0014 \\
Female & 0.0000 & 0.0000 & - & - \\
Frugivory & 4.6605 & 2.1439 & 4.73 & 0.0297 \\
Insectivory & 0.0000 & 0.0000 & - & - \\
Patagial area & 0.0020 & 0.0008 & 6.37 & 0.0116 \\
Nycteribiid abundance & & & & \\
Intercept & 2.1488 & 0.8974 & 5.73 & 0.0166 \\
Male & -0.5256 & 0.2529 & 4.32 & 0.0377 \\
Female & 0.0000 & 0.0000 & - & - \\
Juvenile & 0.9577 & 0.3023 & 10.04 & 0.0015 \\
Subadult & 0.2233 & 0.3949 & 0.32 & 0.5718 \\
Adult & 0.0000 & 0.0000 & - & - \\
Frugivory & 1.5739 & 0.7222 & 4.75 & 0.0293 \\
Insectivory & 0.0000 & 0.0000 & - & - \\
Patagial area & -0.0007 & 0.0003 & 5.29 & 0.0215 \\
Total ectoparasite abundance & & & \\
Intercept & 0.3516 & 0.1742 & 4.07 & 0.0435 \\
Male & -0.3576 & 0.1822 & 3.85 & 0.0497 \\
Female & 0.0000 & 0.0000 & - & - \\
Frugivory & 0.3827 & 0.1818 & 4.43 & 0.0352 \\
Insectivory & 0.0000 & 0.0000 & - & - \\
\hline
\end{tabular}

ble 3). The findings reveal that the difference in the logs of expected total ectoparasite abundance is expected to be 0.3827 unit higher for individuals exhibiting frugivory (L. angolensis) compared to those exhibiting insectivory (H. jonesi). Also, the expected log total ectoparasite count for males is 0.3576 lower than the expected log count for females while holding the other variables constant in the model.

\section{DISCUSSION}

The present study explicitly revealed fundamental differences in foraging behaviour of bats based on ectoparasite loads. This suggests that ectoparasite prevalence is related to chiropteran diet. Insectivorous bats are noted to be rich in nitrogen (Whitaker 1988) whereas frugivores are poor in nitrogen (Korine et al. 1996, Kam et al. 1997). There is a large array of evidence suggesting that lack of protein inhibits the proper functioning of the immune system (Lochmiller et al. 1993, Vestey et al. 1993, Saino et al. 1997). It was therefore expected that frugivores would have higher ectoparasite loads than insectivores due to suppressed immune system functioning and notable risk of infestation through contaminated plant matter contact (Fogarty et al. 2008). Thus insectivores will have lower loads of ectoparasites (mite, nycteribiid and total ectoparasite abundance) since they mostly catch their prey while in flight minimising contact with contaminated surfaces.

Some bat ectoparasite studies support female-biased parasitism (Christe et al. 2007, Presley and Willig 2008) as was the case in our findings. However, this finding contrasts those of many other mammalian ectoparasite studies. Male 
mammalian species are widely known to harbour more ectoparasites than do females (Moore and Wilson 2002) due to sex-related differences in immunocompetence or home-range size (Morand et al. 2004, Krasnov et al. 2005). Generally the immune system of males is suppressed due to higher levels of androgen (Foldstad and Karter 1992) resulting in greater parasitic loads than those of females. In spite of this, other ecological factors may greatly influence sex-biased parasitism (Krasnov et al. 2005), such as differential roost-site selection (based on sex) and colonysize effects. For instance, more bats are attracted to roosts of high quality selected by females, which makes females more susceptible to infestations (Zahn and Rupp 2004). Also, transmission of ectoparasites is encouraged when females tend to roost in dense maternity colonies for the maintenance of high body temperatures required to promote rapid juvenile growth (McCracken 1984).

When age is taken into account, ectoparasitic loads will differ markedly among chiropterans based on mite, nycteribiid and total ectoparasite abundance. Evidence for horizontal transfers of ectoparasites (encounters between infested and non-infested) through offspring adoption and/ or social interactions, which are common among colonial organisms, has been documented (Altizer et al. 2003, Bize et al. 2003). This mechanism is especially true for both nycteribiids and mites, which are wingless and not highly mobile. Hence, they mostly depend on colonial hosts for their survival and population maintenance rather than solitary hosts that provide limited substrates. Other life history traits or strategies of both hosts and parasites may also influence the intensity and prevalence of bat ectoparasites. For instance, bat flies are holometabolous with pupation having to take place off the host specifically, in the bat's roost (Fritz 1983). In order to feed after eclosion, nycteribiids must immediately locate and colonise a host (Caire et al. 1985), thus making the young of bats 'vulnerable'. This could have led to significantly higher nycteribiid loads among juveniles compared to adults. Though subadults had higher nycteribiid loads, they were not statistically different from adult bats. Furthermore, the restricted energy budget of young bats, especially juveniles, may have accounted for such higher nycteribiid abundance due to the high cost of self-grooming. Most mites such as spinturnicid mites are exclusive ectoparasites of bats, which spend their entire life cycle on the host's patagium (Dowling 2006). They therefore adjust their reproductive cycle to that of the host in order to infest neonates (Christe et al. 2000). Thus, we can argue that adult chiropterans will temporarily have higher mite intensities compared to juveniles and subadults, as was the case in our findings (hence, the statistical insignificance) in lieu of horizontal transfers and restricted energy budgets.

Contrary to evidence that larger habitats (host body size) support more individuals than do smaller habitats (Rosenzweig 1995), host trunk area, which is a surrogate of body size, did not influence mite, nycteribiid and total ectoparasite abundance of chiropterans. This suggests that larger-sized chiropterans will not necessarily have higher ectoparasite loads in a predictable way. If grooming reduces ectoparasite prevalence (Clayton 1991, Cotgreave and Clayton 1994, Mooring 1995, Poiani et al. 2000), juveniles should also have reduced ectoparasite loads because grooming is a common practice among vertebrates.

A study of de Fanis and Jones (1995) study of a captive colony of long-eared bats (Plecotus auritus Linnaeus) revealed the presence of mother-juvenile and adult-adult allogrooming but no evidence of juvenile-juvenile allogrooming. As such, grooming can reduce ectoparasite loads not only in adults but across all age groups of chiropterans. The intensity and period spent grooming may also cause ectoparasites to be spatially localised (Reiczigel and Rózsa 1998). This could have led to the insignificant (negative relationship for all analyses) contribution of host trunk area to mite, nycteribiid and total ectoparasite abundance since the area is readily exposed to grooming. Contrary to host trunk area, patagium has a significant effect on mite and nycteribiid abundance probably due to less grooming accessibility. The significance of patagial area could also be attributed to morphological adaptations and preferences of ectoparasites for resource partitioning, thus restricting them to chiropteropatagium. This may have accounted for the significantly positive relationship between patagia and mite abundance contrary to the significantly negative relationship between patagia and nycteribiid abundance since the former (mite) spends its entire life cycle on the host (specifically the patagium).

Acknowledgements. We thank the anonymous reviewer(s) for helpful comments on early drafts of the manuscript.

\section{REFERENCES}

Agresti A. 2002: Categorical Data Analysis. Second Edition. John Wiley and Sons, New York, $710 \mathrm{pp}$.

Altizer S., Nunn C.L., Thrall P.H., Gittleman J.L., Antonovics J., Cunningham A.A., Dobson A.P., EzenQA V., Jones K.E., Peersen A.B., Poss M., Pulliam J.R.C. 2003: Social organization and parasite risk in mammals: integrating theory and empirical studies. Annu. Rev. Ecol. Evol. Syst. 34: 517-547.

Bell G., Burt A. 1991: The comparative biology of parasite species diversity: internal helminths of freshwater fish. J. Anim. Ecol. 60: 1047-1064.
Bize P., Roulin A., Richner H. 2003: Adoption as an offspring strategy to reduce ectoparasite exposure. Proc. Biol. Sci. 270, suppl.: S114-S116.

Bordes F., Morand S., Ricardo G. 2008: Bat fly species richness in Neotropical bats: correlations with host ecology and host brain. Oecologia 158: 109-116.

Brown C.R., Brown M.B. 1986: Ectoparasitism as a cost of coloniality in cliff swallows Hirundo pyrrhonota. Ecology 67: 1206-1218.

Bruyndonckx N., Dubey S., Ruedi M., Christe P. 2009: Molecular cophylogenetic relationships between European bats and their ectoparasitic mites (Acari, Spinturnicidae). Mol. Phylogenet. Evol. 51: 227-237. 
Caire W., Hornuff L., Sohrabi N. 1985: Stimuli used by Trichobius major (Diptera, Streblidae) to locate its bat host, Myotis velifer. Southwest. Nat. 30: 405-412.

Christe P., Arlettaz R., Vogel P. 2000: Variation in intensity of a parasitic mite (Spinturnix myoti) in relation to the reproductive cycle and immunocompetence of its bat host (Myotis myotis). Ecol. Lett. 3: 207-212.

Christe P., Glaizot O., Evanno G., Bruyndonckx N., Devevey G., Yannic G., Patthey P., Maeder A., Vogel P., Arlettaz R. 2007: Host sex and ectoparasites choice: preference for, and higher survival on female hosts. J. Anim. Ecol. 76: 703-710.

Clayton D.H. 1991: Coevolution of avian grooming and ectoparasite avoidance. In: J.E. Loye and M. Zuk (Eds.), Bird-Parasite Interactions: Ecology, Evolution and Behaviour. Oxford University Press, Oxford, pp. 258-289.

Clayton D.H., Lee P.L.M., Tompkins D.M., Brodie E.D.I. 1999: Reciprocal natural selection on host-parasite phenotypes. Am. Nat. 154: 261-270.

Cotgreave P., Clayton D.H. 1994: Comparative analysis of time spent grooming by birds in relation to parasite load. Behaviour 131: 171-187.

Dick C.W. 2007: High host specificity of obligate ectoparasites. Ecol. Entomol. 32: 446-450.

Dormaa Municipal Assembly 2006: http://dormaa.ghanadistricts.gov.gh/, A public-private partnership programme between the ministry of local government and rural development and maks publications and media services, Ghana, 09/2014.

Dowling A.P.G. 2006: Mesostigmatid mites as parasites of small mammals: Systematics, ecology, and the evolution of parasitic associations. In: S. Morand, B.R. Krasnov and P. Poulin (Eds.), Micromammals and Macroparasites from Evolutionary Ecology to Management. Springer-Verlag, Tokyo, pp. 103-117.

ECKSTEIN R.A., HART B.L. 2000: Grooming and control of fleas in cats. Appl. Anim. Behav. Sci. 68: 141-150.

Emerson S.B., Greene H.W., Charnov E.L. 1994: Allometric aspects of predator-prey interactions. In: P. Wainwright and S. Reilly (Eds.), Ecological Morphology: Integrative Organismal Biology. University of Chicago Press, Chicago, pp. 123-139.

De Fanis E., Jones G. 1995: Post-natal growth, mother-infant interactions and development of vocalizations in the vespertilionid bat Plecotus auritus. J. Zool. 235: 85-97.

Fitze P.S., Tschirren B., Richner H. 2004: Life history and fitness consequences of ectoparasites. J. Anim. Ecol. 73: 216-226.

Fogarty R., Halpin K., Hyatt A.D., Daszak P., Mungall B.A. 2008: Henipavirus susceptibility to environmental variables. Virus Res. 132: 140-144.

Folstad I., Karter A.J. 1992: Parasites, bright males, and the immunocompetence handicap. Am. Nat. 139: 603-622.

Fritz G.N. 1983: Biology and ecology of bat flies (Diptera: Streblidae) on bats in the genus Carollia. J. Med. Entomol. 20: 1-10

Gannon M.R., Willig M.R. 1995: Ecology of ectoparasites from tropical bats. Environ. Entomol. 24: 1495-1503.

Gay N., Olival K.J., Bumrungsri S., Siriaroonrat B., BourGarel M., Morand S. 2014: Parasite and viral species richness of Southeast Asian bats: fragmentation of area distribution matters. Int. J. Parasitol. Parasites Wildl. 3: 161-170.

Giannini N.P., Kalko E.K.V. 2004: Trophic structure in a large assemblage of phyllostomid bats in Panama. Oikos 105: 209220.

Giorgi M.S., Arlettaz R., Christe P., Vogel P. 2001: The energetic grooming costs imposed by a parasitic mite (Spinturnix myoti) upon its bat host (Myotis myotis). Proc. Biol. Sci. 268: 2071-2075.

HART B.L. 1992: Behavioral adaptations to parasites: an ethological approach. J. Parasitol. 78: 256-265.

Hill J.E., Sмiтн J.D. 1984: Bats: a Natural History. University of Texas Press, Austin, 243 pp.
Holmes J.L. 2002: Roosting ecology of the grey headed flying fox, Pteropus poliocephalus: spatial distribution in a summer camp. MSc Thesis, University of Tennessee, Knoxville, 53 pp.

Kam M., Khokhlova I.S., Degen A.A. 1997: Granivory and plant selection by desert gerbils of different body size. Ecology 78: 2218-2229.

Korine C., Arad Z., Arieli A. 1996: Nitrogen and energy balance of the fruit bat, Rousettus aegyptiacus, on natural fruit diets. Physiol. Zool. 69: 618-634.

Krasnov B.R., Morand S., Hawlena H., Khokhlova I.S., Shenbrot G.I. 2005: Sex-biased parasitism, seasonality and sexual size dimorphism in desert rodents. Oecologia 146: 209 217.

Lehane M. 2005: The Biology of Blood-sucking Insects. Second Edition. Cambridge University Press, Cambridge, $321 \mathrm{pp}$

LeHMANN T. 1993: Ectoparasites: direct impact on host fitness. Parasitol. Today 9: 8-13.

Lochmiller R.L., Vestey M.R., Boren J.C. 1993: Relationship between protein nutritional status and immuno-competence in northern bobwhite chicks. Auk 110: 503-510.

LUČAN R.K. 2006: Relationships between the parasitic mite Spinturnix andegavinus (Acari: Spinturnicidae) and its bat host, Myotis daubentonii (Chiroptera: Vespertilionidae): seasonal, sex- and age-related variation in infestation and possible impact of the parasite on the host condition and roosting behaviour. Folia Parasitol. 53: 147-152.

Marshall A.G. 1981: The Ecology of Ectoparasitic Insects. Academic Press, New York, 459 pp.

MCCracken G.F. 1984: Communal nursing in Mexican free-tailed bat maternity colonies. Science 223: 1090-1091

Moore S.L., Wilson K. 2002: Parasites as viability cost of sexual selection in natural populations of mammals. Science 297: 2015-2018.

Mooring M.S. 1995: The effect of tick challenge on grooming rate by impala. Anim. Behav. 50: 377-392.

Mooring M.S., Samuel W.M. 1999: Premature loss of winter hair in free-ranging moose (Alces alces) infested with winter ticks (Dermacentor albipictus) is correlated with grooming rate. Can. J. Zool. 77: 148-156.

Morand S., De Belloce J.G., Stanko M., Miklisová D. 2004: Is sex-biased ectoparasitism related to sexual size dimorphism in small mammals of Central Europe? Parasitology 129: 505-510.

NeLson J. 1965: Movements of Australian flying foxes (Pteropodidae: Megachiroptera). Aust. J. Zool. 13: 53.

Poiani A., Goldsmith A.R., Evans M.R. 2000: Ectoparasites of house sparrows (Passer domesticus): an experimental test of the immunocompetence handicap hypothesis and a new model. Behav. Ecol. Sociobiol. 47: 230-242.

Presley S. J., Willig M.R. 2008: Intraspecific patterns of ectoparasite abundances on Paraguayan bats: effects of host sex and body size. J. Trop. Ecol. 24: 75-83.

RACEY P.A. 1988: Reproductive assessment in bats. In: T.H. Kunz (Ed.), Ecological and Behavioral Methods for the Study of Bats. Smithsonian Institution Press, Washington D.C., pp. 31-45.

Reckardt K., Kerth G. 2009: Does the mode of transmission between hosts affect the host choice strategies of parasites? Implications from a field study on bat fly and wing mite infestation of Bechstein's bats. Oikos 118: 183-190.

ReICZIGEL J., Rózsa L. 1998: Host-mediated site segregation of ectoparasites: an individual-based simulation study. J. Parasitol. 84: 491-498.

Reinhardt K., Siva-Jothy M.T. 2007: Biology of the bed bugs (Cimicidae). Annu. Rev. Entomol. 52: 351-374.

RitZi C.M., WhitaKer J.O. 2003: Ectoparasites of small mammals from the Newport chemical depot, Vermillion County, Indiana. Northeast. Nat. 10: 149-158.

Rosenzweig M.L. 1995: Species Diversity in Space and Time. Cambridge University Press, Cambridge, 436 pp. 
Saino N., Calza S., Moller A.P. 1997: Immunocompetence of nestling barn swallows in relation to brood size and parental effort. J. Anim. Ecol. 66: 827-836.

Vardon M.J., Tidemann, C.R. 1998: Reproduction, growth and maturity in the black flying-fox, Pteropus alecto (Megachiroptera: Pteropodidae). Aust. J. Zool. 46: 329.

Vestey M.R., McMurry S.T., Lochmiller R.L. 1993: Influence of dietary protein on selected measures of humoral and cellular immunity in the cotton rat Sigmodon hispidus. Can. J. Zool. 71: 579-586.

Vitone N.D., Altizer S., Nunn C.L. 2004: Body size, diet and sociality influence the species richness of parasitic worms in anthropoid primates. Evol. Ecol. Res. 6: 183-199.
Wenzel R.L., Tipton V.J. 1966: Some relationships between mammal hosts and their ectoparasites. In: R. L. Wenzel and V. J. Tipton (Eds.), Ectoparasites of Panama. Field Museum of Natural History. Chicago, pp. 677-723.

Whitaker J.O. 1988: Food habits analysis of insectivorous bats. In: T. H. Kunz (Ed.), Ecological and Behavioral Methods for the Study of Bats. Smithsonian Institution Press, Washington D.C., pp. 171-190.

ZAHN A., RupP D. 2004: Ectoparasite load in European vespertilionid bats. J. Zool. 262: 383-391.

Cite this article as: Luguterah A., Lawer E.A. 2015: Effect of dietary guild (frugivory and insectivory) and other host characteristics on ectoparasite abundance (mite and nycteribiid) of chiropterans. Folia Parasitol. 62: 021. 